\title{
Relationship between hemoglobin and insulin-like growth factor- 1 in children and adolescents with idiopathic short stature
}

\author{
Qianqian Zhao ${ }^{1,2}$, Mei Zhang ${ }^{1,2}$, Baolan $\mathrm{Ji}^{1,2}$, Yuntian $\mathrm{Chu}^{3}$, Hui Pan ${ }^{4,2}$, Wenhua Yan ${ }^{1,2^{*}+}$ and Bo Ban ${ }^{1,2^{* *}}$ (D)
}

\begin{abstract}
Background: The growth hormone/insulin-like growth factor-1 (GH/IGF-1) axis is critical for the regulation of children's growth and development. Serum IGF-1 concentrations are usually low in individuals with idiopathic short stature (ISS) despite normal endogenous GH levels, and the associated underlying factors are unknown. This study aimed to explore the relationship between IGF-1 and hemoglobin $(\mathrm{Hb})$ in children with ISS.

Methods: A cross-sectional analysis was performed including 178 children and adolescents with ISS who were enrolled from March 2013 to February 2019. The related clinical and biochemical parameters were evaluated for each patient. Univariate analysis, smooth curve fitting and multivariate piecewise linear regression were performed.

Result: The mean levels of IGF-1 standard deviation scores (SDS) and Hb were $-0.99(-1.60--0.09)$ and $131.81 \pm$ $9.36 \mathrm{~g} / \mathrm{L}$, respectively. Univariate analysis displayed a significant positive association between $\mathrm{Hb}$ and IGF-1 SDS $(P<$ 0.001). After adjusting for potential confounding factors, the positive relationship between Hb and IGF-1 SDS remained $(P=0.001)$. Furthermore, there was an inflection point for $\mathrm{Hb}$ in the curve. In a multivariate piecewise linear regression model, IGF-1 SDS was significantly positively associated with $\mathrm{Hb}$ when $\mathrm{Hb}$ concentrations were lower than $145 \mathrm{~g} / \mathrm{L}$ (B 0.05; 95\% Cl 0.02, 0.07; $P<0.001$ ). However, IGF-1 SDS decreased with increasing Hb levels when $\mathrm{Hb}$ concentrations were greater than $145 \mathrm{~g} / \mathrm{L}(\mathrm{B}-0.15 ; 95 \% \mathrm{Cl}-0.23,-0.06 ; P=0.001)$.

Conclusion: This study demonstrated that $\mathrm{Hb}$ is associated with IGF-1 in Chinese children and adolescents with ISS. The levels of IGF-1 increased with the elevation of $\mathrm{Hb}$, but when the concentration of $\mathrm{Hb}$ exceeded a certain range, with the increase of $\mathrm{Hb}$, IGF-1 decreased instead.
\end{abstract}

Keywords: Insulin-like growth factor-1, Hemoglobin, Idiopathic short stature

\section{Background}

Idiopathic short stature (ISS) is defined by a height more than two standard deviation scores (SDS) below the median height for the relevant age and sex of the subject for whom, with the currently available diagnostic tools, no etiology has been established [1]. Although there are

\footnotetext{
*Correspondence: ywh123456@163.com; banbo2011@163.com

${ }^{+}$Wenhua Yan and Bo Ban contributed equally to this work.

'Department of Endocrinology, Affiliated Hospital of Jining Medical

University, Jining Medical University, 89 Guhuai Road, Jining, Shandong 272029, P.R. China

Full list of author information is available at the end of the article
}

no clear causes, several studies have attempted to identify potential mechanisms for impaired linear growth in children with ISS $[2,3]$. The growth hormone/insulinlike growth factor-1 (GH/IGF-1) axis is central to the regulation of child growth and development during critical periods. Many children with ISS have low IGF-1 levels despite normal endogenous GH levels [4]. A previous study has shown that a substantial proportion of children with ISS had an impaired GH/IGF-1 axis [5].

Therefore, investigating factors associated with IGF-1 can contribute to understanding the underlying

(c) The Author(s). 2020 Open Access This article is licensed under a Creative Commons Attribution 4.0 International License, which permits use, sharing, adaptation, distribution and reproduction in any medium or format, as long as you give appropriate credit to the original author(s) and the source, provide a link to the Creative Commons licence, and indicate if changes were made. The images or other third party material in this article are included in the article's Creative Commons licence, unless indicated otherwise in a credit line to the material. If material is not included in the article's Creative Commons licence and your intended use is not permitted by statutory regulation or exceeds the permitted use, you will need to obtain permission directly from the copyright holder. To view a copy of this licence, visit http://creativecommons.org/licenses/by/4.0/. The Creative Commons Public Domain Dedication waiver (http://creativecommons.org/publicdomain/zero/1.0/) applies to the data made available in this article, unless otherwise stated in a credit line to the data. 
mechanisms of ISS. We previously reported that uric acid (UA) and low-density lipoprotein cholesterol (LDLC) are associated with IGF-1 [6, 7]. In the present study, we explored the association of hemoglobin $(\mathrm{Hb})$ levels with IGF-1. Many studies have demonstrated that $\mathrm{Hb}$ is significantly associated with the linear growth of children [8]. There are certain long-term complications for childhood with low concentrations of $\mathrm{Hb}$, particularly leading to curbed growth [9]. However, the mechanism by which $\mathrm{Hb}$ may be related to linear growth is largely unknown. One possible mechanism could be that $\mathrm{Hb}$ improves tissue oxygenation, which subsequently enhances optimal cell proliferation and physical growth $[10,11]$. Soliman et al. pointed out the possible relationship between low concentrations of $\mathrm{Hb}$ and impaired IGF-1 [12]. On the other hand, excessive Hb levels also have adverse effects on children's growth and development. High $\mathrm{Hb}$ concentrations are a risk factor for hypertension and adverse pregnancy outcomes. Potential mechanisms include oxidative stress, increased blood viscosity, and impaired systemic response to inflammation and infection [13-15], which might negatively impact the linear growth of children [16]. However, no study has focused on investigating the relationship between high $\mathrm{Hb}$ concentrations and growth indicators.

Recent studies have demonstrated the relationships between IGF-1 levels and $\mathrm{Hb}$ in different populations, including nondiabetic adults [17], aged adults [18] and children with premature adrenarche (PA) [19]. Given that both IGF-1 and $\mathrm{Hb}$ are associated with childhood growth and development, an association analysis between IGF-1 and $\mathrm{Hb}$ in children with short stature may be helpful to further elucidate the pathogenesis of short stature. Unfortunately, at present, a literature review of the relationship between $\mathrm{Hb}$ and IGF-1 in ISS has not been performed. The present study aimed to investigate the relationship between $\mathrm{Hb}$ and IGF-1 in children and adolescents with ISS.

\section{Methods \\ Subjects}

The subjects were enrolled from March 2013 to February 2019 from the Department of Endocrinology, Affiliated Hospital of Jining Medical University. The subjects were part of the GDDSD study (Growth and Development Diseases in Shandong Province: a cohort followup study, http://www.chictr.org.cn, ChiCTR1900026510). Data for the analysis were extracted from the Affiliated Hospital of Jining Medical University information system. A total of 178 children and adolescents with ISS (138 males and 40 females) with an average age of $10.4 \pm 3.8$ years were enrolled. The subjects with height SDS lower than or equal to -2 SD after adjusting for age and sex, an appropriate birth weight for gestational age, and GH sufficiency confirmed by a $\mathrm{GH}$ concentration $>10 \mathrm{ng} / \mathrm{mL}$ in at least two $\mathrm{GH}$ provocative tests were included in the study. The exclusion criteria included children with GH deficiency, skeletal dysplasia, thyroid dysfunction, chronic anemia or other known causes of short stature, including Prader-Willi syndrome, Turner syndrome or having been small for gestational age. In addition, children treated with medication interfering with $\mathrm{GH}$ secretion or its action were also excluded. The flow chart of the study selection process is shown in Fig. 1.

\section{Anthropometry measurements}

All anthropometric measurements were obtained according to standard procedures. Height was measured to the nearest $0.1 \mathrm{~cm}$ without shoes using a stadiometer (Nantong Best Industrial Co., Ltd., Jiangsu, China). Weight was measured by an electronic scale to the nearest $0.1 \mathrm{~kg}$ (Wuxi Weigher Factory Co., Ltd., Jiangsu, China) while the individual was wearing light clothes without shoes. Height SDS were expressed using the growth curve of Chinese children as a reference [20]. Body mass index (BMI) was calculated as the ratio of the weight divided by the square of the height in meters. Puberty stage was evaluated by physical examination based on the Tanner stages [21]. Individuals meeting the following criteria were considered prepubescent: boys with no pubic hair and a testicular volume less than $4 \mathrm{~mL}$ and girls with no pubic hair and no breast development.

\section{Laboratory measurements}

Fasting blood samples were obtained from all subjects to measure laboratory parameters. Two stimulating tests were performed for $\mathrm{GH}$ (500 mg of levodopa for those weighing more than $30 \mathrm{~kg}$ and $250 \mathrm{mg}$ of levodopa for those weighing less than $30 \mathrm{~kg}$, orally, and $0.1 \mathrm{U} / \mathrm{kg}$ insulin, subcutaneously). A chemiluminescence method was used to assess serum GH concentrations (Access 2, Beckman Coulter, USA), and the sensitivity was $0.010 \mu \mathrm{g} / \mathrm{L}$. Serum IGF-1 was measured by a chemiluminescence assay (DPC IMMULITE 1000 analyzer, SIEMENS, Germany) with intra- and interassay coefficients of variation (CVs) of 3.0 and $6.2 \%$, respectively. $\mathrm{Hb}$ was measured by an automatic blood analyzer (XN20 (Al), SYSMEX, Japan). Fasting plasma glucose (FPG), kidney function (including creatinine $(\mathrm{Cr})$, blood urea nitrogen (BUN) and UA), Alanine aminotransferase (ALT) and lipid profiles (including triglycerides (TG), total cholesterol (TC), high-density lipoprotein cholesterol (HDL-C), and LDL-C) were determined by an automatic biochemical analyzer (Cobas c702, Roche, Shanghai, China). Measures of estradiol and testosterone were tested by a luminescence immunoassay system (Cobas e 602, Roche, Shanghai, China). IGF-1 
871 children and adolescents with short stature who were enrolled from

March 2013 to February 2019 from the Department of Endocrinology,

Affiliated Hospital of Jining Medical University
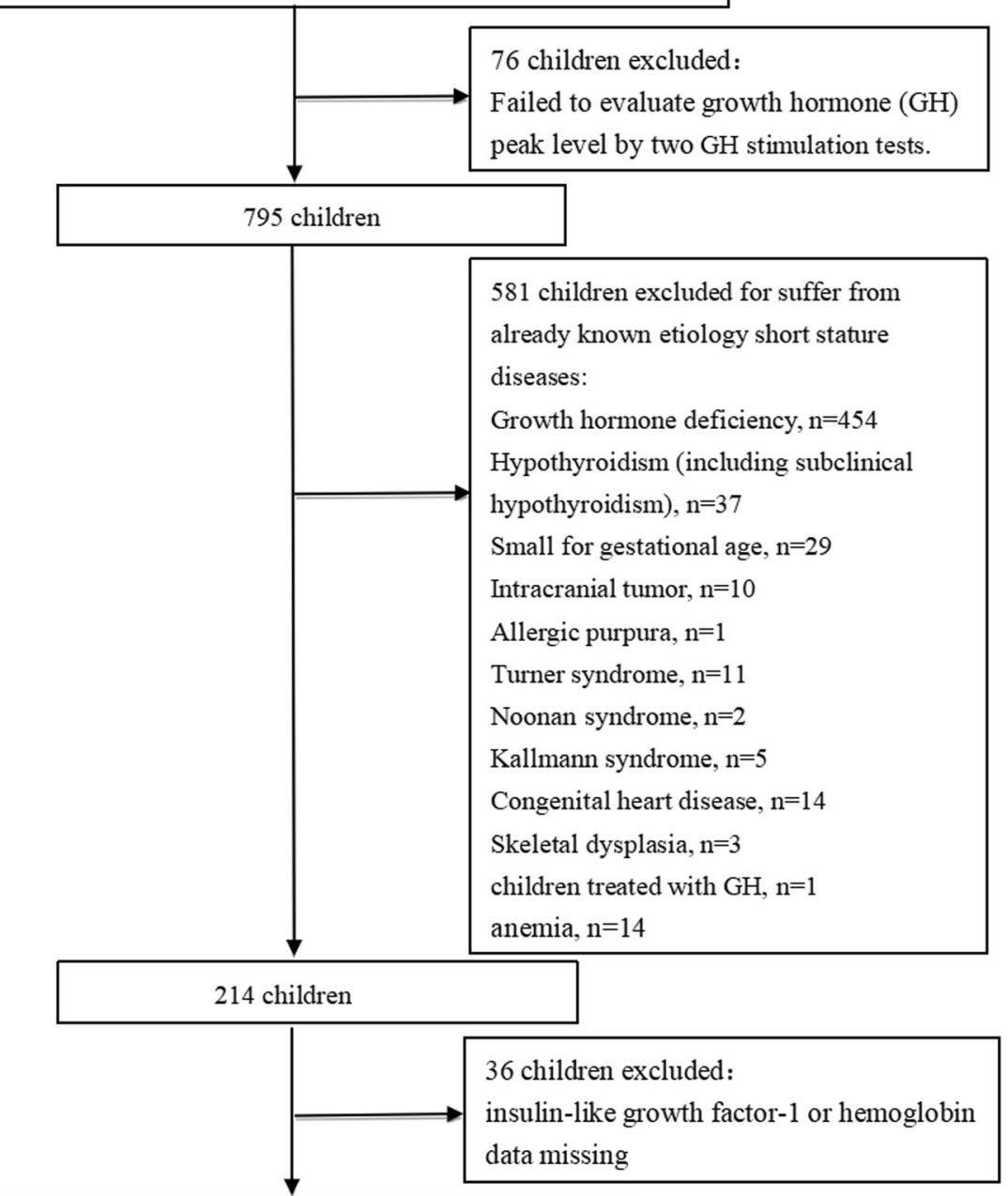

idiopathic short stature enrolled in the study $(\mathrm{n}=178)$

Fig. 1 Flow chart of the study population

SDS were calculated based on IGF-1 levels matched to both age and sex healthy children and adolescents Japanese data [22].

\section{Statistical analysis}

Normally distributed variables are displayed as the mean \pm standard deviation, nonnormally distributed variables are displayed as the median (interquartile range), and categorical variables are expressed using a number and percentage (Table 1). Univariate analysis (Table 2) was used to assess whether $\mathrm{Hb}$ and other variables were associated with IGF-1 SDS. Multiple linear regression and piecewise linear regression was further used to examine the independent association and threshold effect of IGF-1 SDS and $\mathrm{Hb}$ (Table 3). The flow chart of the study selection process is shown in Fig. 1. Smooth curve fitting was used to explore the relationship between IGF-1 SDS and Hb (Fig. 2). A two-tailed $P<0.05$ was considered statistically significant in all analyses. Statistical analysis was performed with R 3.4.3 (https:// www.R-project.org) and EmpowerStats (https://www. empowerstat s.com, X\&Y Solutions, Inc., Boston, MA).

\section{Results}

Clinical and biochemical characteristics

The baseline characteristics of the participants are displayed in Table 1. A total of 178 children, consisting of 138 (77.53\%) males and 40 (22.47\%) females, were recruited. The mean or median values (interquartile range) of the anthropometric measurements and biomarkers 
Table 1 Clinical and biochemical characteristics

\begin{tabular}{|c|c|}
\hline Variables & All \\
\hline N & 178 \\
\hline Sex (male \%) & $138(77.53 \%)$ \\
\hline Age (years) & $10.4 \pm 3.8$ \\
\hline Bone age (years) & $8.5 \pm 4.1$ \\
\hline Height (cm) & $126.47 \pm 19.62$ \\
\hline Height SDS & $-2.71(-3.18--2.31)$ \\
\hline Mother's height (cm) & $155.38 \pm 5.54$ \\
\hline Father's height (cm) & $167.59 \pm 5.41$ \\
\hline Body weight (kg) & $27.29 \pm 10.76$ \\
\hline BMI $\left(\mathrm{kg} / \mathrm{m}^{2}\right)$ & $16.38 \pm 2.57$ \\
\hline IGF-1 (ng/mL) & $175.50(90.05-273.75)$ \\
\hline IGF-1 SDS & $-0.99(-1.60--0.09)$ \\
\hline $\mathrm{Hb}(\mathrm{g} / \mathrm{L})$ & $131.81 \pm 9.36$ \\
\hline $\mathrm{Cr}$ (umol/L) & $38.75 \pm 9.75$ \\
\hline BUN (umol/L) & $4.65 \pm 1.15$ \\
\hline UA (umol/L) & $268.55 \pm 75.63$ \\
\hline $\mathrm{TG}(\mathrm{mmol} / \mathrm{L})$ & $0.65 \pm 0.24$ \\
\hline TC (mmol/L) & $3.79 \pm 0.66$ \\
\hline $\mathrm{HDL}(\mathrm{mmol} / \mathrm{L})$ & $1.35 \pm 0.27$ \\
\hline LDL (mmol/L) & $2.07 \pm 0.51$ \\
\hline $\mathrm{ALT}(\mathrm{U} / \mathrm{L})$ & $15.68 \pm 6.87$ \\
\hline FPG (mmol/L) & $4.80 \pm 0.58$ \\
\hline Estradiol (pg/mL) & $17.83(11.80-26.79)$ \\
\hline Testosterone (ng/mL) & $0.25(0.10-0.86)$ \\
\hline \multicolumn{2}{|l|}{ Pubertal stage } \\
\hline Prepubertal (\%) & 129 (72.47\%) \\
\hline Pubertal (\%) & 49 (27.53\%) \\
\hline
\end{tabular}

Abbreviations: Height SDS height standard deviation scores, $B M I$ body mass index, IGF-1 SDS insulin like growth factor-1 standard deviation scores, $\mathrm{Hb}$ hemoglobin, $\mathrm{Cr}$ creatinine, BUN blood urea nitrogen, UA uric acid, TG triglyceride, TC total cholesterol, HDL-C high density lipoprotein-cholesterol, $L D L-C$ low density lipoprotein cholesterol, ALT alanine aminotransferase, FPG fasting plasma glucose

Normal distribution of data was presented as mean \pm standard deviation nonnormal distribution of data was presented as median (interquartile range) and categorical data using number (percentage)

among participants aged $10.4 \pm 3.8$ years old were described. The mean bone age of the subjects was $8.5 \pm 4.1$ years, and the median and interquartile range of height SDS was - 2.71 (-3.18--2.31). A total of $129(72.47 \%)$ subjects were prepubescent, and only 49 (27.53\%) were pubescent. The mean levels of IGF-1 SDS and Hb were $-0.99(-1.60--0.09)$ and $131.81 \pm 9.36 \mathrm{~g} / \mathrm{L}$, respectively.

\section{Factors associated with IGF-1 SDS in the subjects}

Table 2 shows the associations between IGF-1 SDS and all tested variables by univariate analysis. A significant positive relationship between IGF-1 SDS and $\mathrm{Hb}$ was observed $(P<0.001)$. Other variables, including age,
Table 2 Association between IGF-1 SDS and different variables $(n=178)$

\begin{tabular}{|c|c|c|c|}
\hline Variables & $\mathrm{B}$ & $(95 \% \mathrm{Cl})$ & $P$ value \\
\hline Age (years) & 0.10 & $(0.06,0.15)$ & $<0.001$ \\
\hline Bone age (years) & 0.11 & $(0.07,0.15)$ & $<0.001$ \\
\hline Height SDS & 0.60 & $(0.32,0.89)$ & $<0.001$ \\
\hline Mother's height (cm) & -0.01 & $(-0.04,0.03)$ & 0.739 \\
\hline Father's height (cm) & 0.01 & $(-0.03,0.04)$ & 0.735 \\
\hline Body weight (kg) & 0.06 & $(0.04,0.07)$ & $<0.001$ \\
\hline BMI $\left(\mathrm{kg} / \mathrm{m}^{2}\right)$ & 0.20 & $(0.13,0.26)$ & $<0.001$ \\
\hline $\mathrm{Hb}(\mathrm{g} / \mathrm{L})$ & 0.04 & $(0.03,0.06)$ & $<0.001$ \\
\hline $\mathrm{Cr}$ (umol/L) & 0.03 & $(0.01,0.05)$ & $<0.001$ \\
\hline BUN (umol/L) & -0.03 & $(-0.20,0.13)$ & 0.697 \\
\hline UA (umol/L) & 0.01 & $(0.00,0.01)$ & 0.017 \\
\hline TG $(\mathrm{mmol} / \mathrm{L})$ & 0.29 & $(-0.51,1.09)$ & 0.480 \\
\hline TC (mmol/L) & -0.20 & $(-0.50,0.09)$ & 0.177 \\
\hline $\mathrm{HDL}(\mathrm{mmol} / \mathrm{L})$ & -0.36 & $(-1.08,0.35)$ & 0.316 \\
\hline $\mathrm{LDL}(\mathrm{mmol} / \mathrm{L})$ & -0.25 & $(-0.63,0.13)$ & 0.193 \\
\hline $\mathrm{ALT}(\mathrm{U} / \mathrm{L})$ & 0.02 & $(-0.01,0.05)$ & 0.145 \\
\hline FPG (mmol/L) & 0.41 & $(0.08,0.74)$ & 0.014 \\
\hline Estradiol (pg/mL) & 0.02 & $(0.01,0.03)$ & $<0.001$ \\
\hline Testosterone (ng/mL) & 0.35 & $(0.17,0.53)$ & $<0.001$ \\
\hline \multicolumn{4}{|l|}{ Sex } \\
\hline Male & reference & & \\
\hline Female & -0.33 & $(-0.76,0.11)$ & 0.142 \\
\hline \multicolumn{4}{|l|}{ Pubertal stage } \\
\hline Prepubertal (\%) & reference & & \\
\hline Pubertal (\%) & 0.96 & $(0.55,1.36)$ & $<0.001$ \\
\hline
\end{tabular}

Abbreviations: Height SDS height standard deviation scores, $B M I$ body mass index, $\mathrm{Hb}$ hemoglobin, $\mathrm{Cr}$ creatinine, $\mathrm{BUN}$ blood urea nitrogen, UA uric acid, TG triglyceride, $T C$ total cholesterol, $H D L-C$ high density lipoprotein-cholesterol, $L D L-C$ low density lipoprotein cholesterol, $A L T$ alanine aminotransferase, FPG fasting plasma glucose

$B$ unstandardized regression coefficient. $P<0.05$ is considered to be statistically signifcant

bone age, height SDS, weight, BMI, Cr, estradiol, testosterone, stage of puberty (all $P<0.001)$, UA $(P=$ $0.017)$ and FPG $(P=0.014)$, were all positively associated with IGF-1 SDS.

\section{Independent association between IGF-1 SDS and $\mathrm{Hb}$}

As shown in Table 3, multiple regression was performed after adjustment for potential confounding factors based on the results of the univariate analysis, including age, height, weight, Cr, UA, FPG, estradiol, testosterone, and stage of puberty, to further analyze the independent association between IGF-1 SDS and $\mathrm{Hb}$. The positive relationship between $\mathrm{Hb}$ and IGF-1 SDS remained (B 0.03; 95\% CI $0.01,0.05 ; P=0.001)$. Smooth curve fitting was performed after adjustment for potential confounding factors, and a nonlinear relationship was observed 
Table 3 Threshold effect analysis for the relationship between $\mathrm{Hb}$ and IGF-1 SDS

\begin{tabular}{lll}
\hline Models & IGF-1 SDS & \\
\cline { 2 - 3 } & Adjusted B (95\%Cl) & $P$ value \\
\hline Model I & $0.03(0.01,0.05)$ & 0.001 \\
$\quad$ One line slope $(n=178)$ & & \\
Model II & 145 & $<0.001$ \\
Hemoglobin's inflection point & $0.05(0.02,0.07)$ & 0.001 \\
$<145(n=162)$ & $-0.15(-0.23,-0.06)$ & \\
$>145(n=16)$ & 0.044 & \\
LRT test &
\end{tabular}

Model I, linear analysis; Model II, nonlinear analysis. LRT test, logarithmic likelihood ratio test ( $p$-value $<0.05$ indicates that Model II is significantly different from Model I, which indicates a nonlinear relationship); adjustment variables: age, sex, BMI, TC, pubertal stage $B M I$ body mass index, $T C$ total cholesterol

$B$ unstandardized regression coefficient; $P<0.05$ was considered to be statistically significant

between IGF-1 SDS and Hb. A two-stage change and an inflection point were displayed in the resultant curve (Fig. 2a). A scatter plot of the distribution of child $\mathrm{Hb}$ and IGF-1 SDS was presented in Fig. 2b. Specifically, there was a positive association between IGF-1 SDS and $\mathrm{Hb}$ when the concentration of $\mathrm{Hb}$ was lower than the turning point. However, there was a negative association between IGF-1 SDS and $\mathrm{Hb}$ when the concentration of $\mathrm{Hb}$ was beyond the turning point. In addition, we further applied multivariate piecewise linear regression to evaluate the independent relationship between IGF-1 SDS and $\mathrm{Hb}$ in line with smooth curve fitting, and the inflection point was $145 \mathrm{~g} / \mathrm{L}$ (Table 3). The analysis of threshold effects indicated that IGF-1 SDS increased with the elevation of $\mathrm{Hb}$ when the $\mathrm{Hb}$ concentration was lower than $145 \mathrm{~g} / \mathrm{L}$, for which the mean concentration of
Hb was $130.02 \pm 7.58 \mathrm{~g} / \mathrm{L}$ (B 0.05; 95\% CI 0.02, 0.07; $P<0.001)$, which approximates the normal value recommended by the literature [23]; however, IGF-1 SDS decreased with $\mathrm{Hb}$ elevation when the $\mathrm{Hb}$ concentration was greater than $145 \mathrm{~g} / \mathrm{L}$, for which the mean concentration of $\mathrm{Hb}$ was $149.94 \pm 5.58 \mathrm{~g} / \mathrm{L}$ (B $-0.15 ; 95 \% \mathrm{CI}-0.23$, $-0.06 ; P=0.001)$. In addition, we used the original IGF-1 data to adjust for age and sex and performed an internal analysis between $\mathrm{Hb}$ and IGF-1. We found that the results were consistent with the relationship between $\mathrm{Hb}$ and IGF-1 SDS (data not shown).

\section{Discussion}

A nonlinear relationship was observed between IGF-1 SDS and $\mathrm{Hb}$ in children with ISS. More specifically, our study found that IGF-1 SDS increased as $\mathrm{Hb}$ increased when the $\mathrm{Hb}$ concentration was lower than $145 \mathrm{~g} / \mathrm{L}$. However, when the $\mathrm{Hb}$ concentration further increased, there was a negative association between IGF-1 SDS and $\mathrm{Hb}$.

There is a large number of children and adolescents with short stature in China. An epidemiological study indicated that the incidence of primary and middle school students with short stature in China is approximately $3.16 \%$ [24], but there is still a lack of systematic studies. Furthermore, the pathogenesis of short stature in children and adolescents is understudied. We established a clinical cohort of short stature patients (GDDS D) with the main purpose of exploring the association of clinical indicators in these patients and to provide new insights and evidence for the etiology and subsequent diagnosis of short stature.

This study found a positive relationship between IGF$1 \mathrm{SDS}$ and $\mathrm{Hb}$ when $\mathrm{Hb}$ concentrations were lower than $145 \mathrm{~g} / \mathrm{L}$, which was consistent with previous findings in
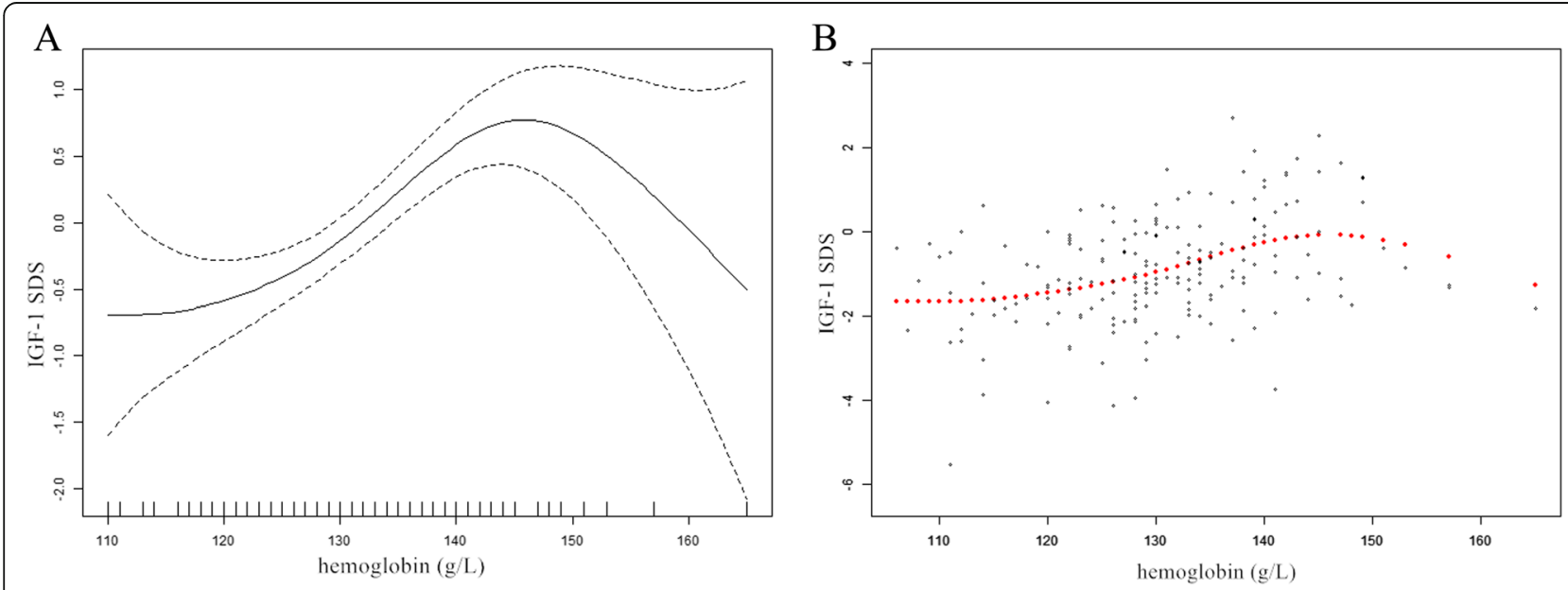

Fig. 2 The relationship between $\mathrm{Hb}$ and IGF-1 SDS by smooth curve fitting $(n=178), P<0.001$. The solid line is the curve fitting line, and the dotted line is the $95 \%$ confidence interval (a). Scatter plot of the distribution of child Hb and IGF-1 SDS (b). Adjustment variables: age, height, weight, Cr, UA, FPG, estradiol, testosterone and pubertal stage. Cr: creatinine; UA: uric acid; FPG: fasting plasma glucose 
other populations [17-19, 25, 26]. Succurro E et al. [17] conducted a study in adult nondiabetic subjects and showed that IGF-1 levels were positively associated with $\mathrm{Hb}$ concentration. However, their study was only based on Caucasian subjects, and the results in other ethnic groups need further exploration. Francesca De Vita et al. [25] demonstrated that the levels of IGF-1 were independent and positively related to $\mathrm{Hb}$ concentration in aged populations. A recent study [19] reported a positive association of IGF-1 concentration with $\mathrm{Hb}$ using a linear regression model in prepubescent children with PA. Vihervuori E et al. conducted a Pearson's correlation analysis in 32 children and described a positive correlation between $\mathrm{Hb}$ and serum IGF-1 levels [26]. Moreover, an observational study conducted in prepubescent children showed that IGF-1 was significantly lower in an anemic group than in a control group [27]. Additionally, an intervention study demonstrated that short-term treatment with iron in children with anemia significantly increased circulating IGF-1 concentrations [28].

Interestingly, we further analyzed the relationship between $\mathrm{Hb}$ and IGF-1 through smooth curve fitting and observed a nonlinear relationship between $\mathrm{Hb}$ and IGF1 SDS. The levels of IGF-1 increased with increasing $\mathrm{Hb}$, and when the concentration of $\mathrm{Hb}$ exceeded a certain range, with the increase in $\mathrm{Hb}$, IGF-1 decreased instead. Previous studies have shown that high $\mathrm{Hb}$ may impact the growth and development of children through mechanisms including inflammation, which may impair growth and development [16]. Our findings suggested that a too high of $\mathrm{Hb}$ is associated with reduced IGF-1 levels.

The potential mechanisms of this phenomenon can be explained as follows: low oxygen conditions at low $\mathrm{Hb}$ concentrations inhibit IGF-1 action through an increase in phosphorylated IGF binding protein-1 (IGFBP-1), which inhibits IGF-I action [29]. Tran Phu V et al. demonstrated in a dietary-induced rat model that gestational anemia attenuates postnatal hippocampal IGF signaling, and hippocampal IGF activation was markedly suppressed [30]. High $\mathrm{Hb}$ concentrations may function through induced oxidative stress, increased blood viscosity, and impaired systemic response to inflammation and infection [13-15] to further impact the linear growth of children. However, the exact mechanism by which high $\mathrm{Hb}$ is associated with low IGF-1 is unclear. Basic experiments are needed to further explore the underlying mechanism of the relationship between high $\mathrm{Hb}$ and low IGF-1.

Because IGF-1 standardization varies, to increase the authenticity and reliability of our study results, we used the original IGF-1 data to perform an internal analysis, and the relationship between $\mathrm{Hb}$ and IGF-1 remained stable and reliable. However, this study has some limitations. First, due to the cross-sectional analysis, no definitive causative relationship can be inferred in the study. Second, the present findings are only based on children with ISS, and different results might be observed in other groups, such as children with GH deficiency. Third, these children are short in stature for unknown reasons and have no other diseases, so the amount of high $\mathrm{Hb}$ is limited, especially in prepubertal children. Finally, although we excluded children who received medication that interferes with $\mathrm{GH}$ secretion or its effects, the history of previous medications was reported by the parents of the children themselves, which may not be accurate.

\section{Conclusion}

We described a nonlinear relationship between $\mathrm{Hb}$ and IGF-1 in Chinese children and adolescents with ISS. IGF-1 levels increased with the elevation of Hb concentration; when the increment of $\mathrm{Hb}$ exceeded a certain range, IGF-1 decreased instead.

\section{Abbreviations \\ IGF-1: Insulin-like growth factor-1; ISS: Idiopathic short stature; Height SDS: Height standard deviation scores; BMI: Body mass index; Hb: Hemoglobin; Cr: Creatinine; BUN: Blood urea nitrogen; UA: Uric acid; TG: Triglyceride; TC: Total cholesterol; HDL-C: High density lipoprotein - cholesterol; LDL-C: Low density lipoprotein cholesterol; ALT: Alanine aminotransferase; FPG: Fasting plasma glucose}

\section{Acknowledgments}

Not applicable.

\section{Authors' contributions}

QZ carried out the studies and drafted the manuscript. MZ participated in design of the study. BJ participated in data collection. YC helped the statistical analysis. HP revised the manuscript. BB and WY participated in concept and design of the study also revising it critically for important intellectual content; and final approval of the version to be published. All authors read and approved the final manuscript.

\section{Funding}

This study was supported by Jining Science and Technology Bureau (No. 2017SMN007). The funding body had no roles in the design of the study and collection, analysis, interpretation of data and in writing the manuscript.

\section{Availability of data and materials \\ The data used to support the findings of this study are available from the corresponding author upon request.}

\section{Ethics approval and consent to participate}

This proposal was reviewed and approved by the Human Ethics Committee of the Affiliated Hospital of Jining Medical University (JYFY-2015-019). Inform all patients' families of the aims of the study, and participants' parents signed informed consent forms.

\section{Consent for publication}

Not applicable.

\section{Competing interests}

The authors declare that they have no competing interests.

\section{Author details}

${ }^{1}$ Department of Endocrinology, Affiliated Hospital of Jining Medical University, Jining Medical University, 89 Guhuai Road, Jining, Shandong 272029, P.R. China. ${ }^{2}$ Chinese Research Center for Behavior Medicine in Growth and Development, 89 Guhuai Road, Jining, Shandong 272029, P.R. 
China. ${ }^{3}$ School of Health Management and Medicine, Tongji Medical College, Huazhong University of Science and Technology, Wuhan, Hubei 430030, P.R. China. ${ }^{4}$ Key Laboratory of Endocrinology of National Health and Family Planning Commission, Department of Endocrinology, Peking Union Medical College Hospital, Chinese Academy of Medical Science and Peking Union Medical College, Beijing 100730, P.R. China.

Received: 4 February 2020 Accepted: 22 July 2020

Published online: 03 August 2020

\section{References}

1. Cohen P, Rogol AD, Deal CL, Saenger P, Reiter EO, Ross JL, Chernausek SD, Savage MO, Wit JM. Consensus statement on the diagnosis and treatment of children with idiopathic short stature: a summary of the growth hormone research society, the Lawson Wilkins pediatric Endocrine Society, and the European Society for Paediatric Endocrinology Workshop. J Clin Endocrinol Metab. 2008;93(11):4210-7.

2. Derraik JGB, Miles HL, Chiavaroli V, Hofman PL, Cutfield WS. Idiopathic short stature and growth hormone sensitivity in prepubertal children. Clin Endocrinol. 2019;91(1):110-7.

3. Inzaghi E, Reiter E, Cianfarani S. The challenge of defining and investigating the causes of idiopathic short stature and finding an effective therapy. Horm Res Paediatr. 2019;92(2):71-83.

4. Stawerska R, Czkwianianc E, Smyczyńska J, Hilczer M, Lewiński A Nutritional status in short stature children is related to both ghrelin and insulin-like growth factor I concentrations. J Pediatr Gastroenterol Nutr. 2017;64(5):812-7.

5. Kumar A, Pal A, Kalaivani M, Gupta N, Jain V. Etiology of short stature in Indian children and an assessment of the growth hormone-insulin-like growth factor axis in children with idiopathic short stature. J Pediatr Endocrinol Metab. 2018;31(9):1009-17.

6. Wang $P$, Ji B, Shao Q, Zhang M, Ban B. Association between insulin-like growth Factor-1 and uric acid in Chinese children and adolescents with idiopathic short stature: a cross-sectional study. Biomed Res Int. 2018; 2018:1-6.

7. Zhao Q, Jiang Y, Zhang M, Chu Y, Ji B, Pan H, Ban B. Low-density lipoprotein cholesterol levels are associated with insulin-like growth factor-1 in short-stature children and adolescents: a cross-sectional study. Lipids Health Dis. 2019:18:120

8. Larson LM, Kubes JN, Ramírez Luzuriaga MJ, Khishen S. H. Shankar a, Prado EL. Effects of increased hemoglobin on child growth, development, and disease: a systematic review and meta-analysis. Ann N Y Acad Sci. 2019; 1450(1):83-104.

9. Choy CC, Desai MM, Park JJ, Frame EA, Thompson AA, Naseri T, Reupena MS, Duckham RL, Deziel NC, Hawley NL. Child, maternal and householdlevel correlates of nutritional status: a cross-sectional study among young Samoan children. Public Health Nutr. 2017;20:1235-47.

10. AT S, De Sanctis V, S K. Anemia and growth. Indian J Endocrinol Metab. 2014;18:S1-5.

11. Kajimura S, Aida K, Duan C. Insulin-like growth factor-binding protein-1 (IGFBP-1) mediates hypoxia-induced embryonic growth and developmental retardation. Proc Natl Acad Sci U S A. 2005;102:1240-5.

12. Soliman AT, De Sanctis $V$, Yassin M, Adel A. Growth and growth hormone insulin like growth factor -I (GH-IGF-I) Axis in chronic Anemias. Acta Biomed. 2017;88(1):101-11.

13. Shimizu Y, Nakazato M, Sekita T, Kadota K, Arima K, Yamasaki H, Takamura N, Aoyagi K, Maeda T. Association between the hemoglobin levels and hypertension in relation to the BMI status in a rural Japanese population: the Nagasaki Islands study. Intern Med. 2014;53(5):435-40.

14. Shimizu Y, Nakazato M, Sekita T, Kadota K, Yamasaki H, Takamura N, Aoyagi K, Maeda T. Association between hemoglobin levels and arterial stiffness for general Japanese population in relation to body mass index status: the Nagasaki Islands study. Geriatr Gerontol Int. 2014;14(4):811-8.

15. Dewey KG, Oaks BM. U-shaped curve for risk associated with maternal hemoglobin, iron status, or iron supplementation. Am J Clin Nutr. 2017; 106(Suppl 6):1694S-702S

16. Starr LM, Scott ME, Koski KG. Protein deficiency and intestinal nematode infection in pregnant mice differentially impact fetal growth through specific stress hormones, growth factors, and cytokines. J Nutr. 2015;145(1):41-50
17. Succurro E, Arturi F, Caruso V, Rudi S, Sciacqua A, Andreozzi F, Hribal $\mathrm{ML}$, Perticone F, Sesti G. Low insulin-like growth factor-1 levels are associated with anaemia in adult non-diabetic subjects. Thromb Haemost. 2011:105(2):365-70.

18. Nilsson-Ehle $H$, Bengtsson BA, Lindstedt G, Mellstrom D. Insulin-like growth factor-1 is a predictor of blood haemoglobin concentration in 70-yr-old subjects. Eur J Haematol. 2005;74(2):111-6.

19. Utriainen $P$, Jaaskelainen J, Voutilainen R. Blood erythrocyte and hemoglobin concentrations in premature adrenarche. J Clin Endocrinol Metab. 2013;98(1):E87-91.

20. Li H, Ji CY, Zong XN, Zhang YQ. Height and weight standardized growth charts for Chinese children and adolescents aged 0 to 18 years. Chinese J Pediatr. 2009;47(7):487-92.

21. Wright CM, Ahmed L, Dunger DB, Preece MA, Cole TJ, Butler G. Can we characterise growth in puberty more accurately? Validation of a new puberty phase specific (PPS) growth chart. Arch Dis Child. 2012; 97(Suppl 1):A100

22. Isojima T, Shimatsu A, Yokoya S, Chihara K, Tanaka T, Hizuka N, Teramoto A, Tatsumi Kl, Tachibana K, Katsumata N. Standardized centile curves and reference intervals of serum insulin-like growth factor-I (IGF-I) levels in a normal Japanese population using the LMS method. Endocr J. 2012:59(9):771-80.

23. Allali S, Brousse V, Sacri AS, Chalumeau M, de Montalembert M. Anemia in children: prevalence, causes, diagnostic work-up, and long-term consequences. Expert Rev Hematol. 2017;10(11):1023-8.

24. Wang Q, Liu DY, Yang LQ, Liu Y, Chen XJ. The epidemic characteristics of short stature in school students. Ital J Pediatr. 2015;41(1):1-6.

25. De Vita F, Maggio M, Lauretani F, Crucitti L, Bandinelli S, Mammarella F, Landi F, Ferrucci L, Ceda GP. Insulin-like growth FACTOR-1 and anemia in older subjects: the INCHIANTI study. Endocr Pract. 2015;21(11):1211-8.

26. Vihervuori $E$, Virtanen $M$, Koistinen $H$, Koistinen $R$, Seppala M, Siimes MA Hemoglobin level is linked to growth hormone-dependent proteins in short children. Blood. 1996;87(5):2075-81.

27. Isguven P, Arslanoglu I, Erol M, Yildiz M, Adal E, Erguven M. Serum levels of ghrelin, leptin, IGF-I, IGFBP-3, insulin, thyroid hormones and cortisol in prepubertal children with iron deficiency. Endocr J. 2007:54(6):985-90.

28. Soliman A, Eldabbagh M, Adel A, Sabt A. 765 linear growth and circulating IGF-I concentrations in children with Iron deficiency Anemia after treatment. Arch Dis Child. 2012;97(Suppl 2):A220.

29. Tsunawaki T, Sakai K, Momomura M, Wachi Y, Matsuzawa Y, Iwashita M. Hypoxia alters phosphorylation status of insulin-like growth factor (IGF)binding protein-1 and attenuates biological activities of IGF-I in HepG2 cell cultures. J Obstet Gynaecol Res. 2013;39(9):1367-73.

30. Tran PV, Fretham SJ, Wobken J, Miller BS, Georgieff MK. Gestational-neonatal iron deficiency suppresses and iron treatment reactivates IGF signaling in developing rat hippocampus. Am J Physiol Endocrinol Metab. 2012;302(3): E316-24.

\section{Publisher's Note}

Springer Nature remains neutral with regard to jurisdictional claims in published maps and institutional affiliations.

Ready to submit your research? Choose BMC and benefit from:

- fast, convenient online submission

- thorough peer review by experienced researchers in your field

- rapid publication on acceptance

- support for research data, including large and complex data types

- gold Open Access which fosters wider collaboration and increased citations

- maximum visibility for your research: over $100 \mathrm{M}$ website views per year

At $\mathrm{BMC}$, research is always in progress.

Learn more biomedcentral.com/submission 